\title{
ARQUIVO, HISTÓRIA E MEMÓRIA: POSSIBILIDADES DE DIÁLOGO ENTRE LUHMANN E FOUCAULT
}

\author{
Rafael Lazzarotto Simioni
}

Universidade de Coimbra, Coimbra, Portugal; UCS/PPGD/FDSM/PPGB, Universidade do Vale do Sapucaí (UNIVÁS). Pouso Alegre, MG. Brasil.

E-mail<simioni2010@gmail.com>

http://dx.doi.org/10.1590/ 0102-6445173-190/97

Michel Foucault legou um dos pensamentos mais sofisticados e sensíveis às estruturas discursivas da sociedade contemporânea. Dada a sua originalidade, o estilo de investigação por ele desenvolvido apresenta relevante interesse científico até hoje.

Outra teoria desse quilate, podemos encontrar no pensamento sistêmico de Niklas Luhmann, que possui alguns pontos em comum com Foucault, mas cuja aproximação parece ficar mais no plano das metáforas do que no plano conceitual. Assim acontece, e. g., com o entendimento do dito pelo não dito em Foucault como uma ilustração da noção de forma de diferença em Luhmann. Ou com a ideia de paradoxo em Luhmann como metáfora das contradições e rupturas discursivas em Foucault.

Em qualquer caso, trata-se apenas do uso reciprocamente metafórico de conceitos que são incomensuráveis entre si. Pois fazem parte de perspectivas teóricas muito diferentes, tanto em seus pressupostos teóricos quanto em seus esquemas de observação.

Entretanto, a noção de arquivo em Michel Foucault permite uma conexão com o conceito de memória em Niklas 
Luhmann. Isso porque o arquivo pode significar, ao mesmo tempo, o domicílio do arquivo e o seu poder de consignação. Tal como o arkheion grego, que significava tanto o "lugar" dos arquivos oficiais, quanto o poder de consignação que ele produz: o poder de (con) signar, de reunir signos.

Nessa perspectiva, a pesquisa que originou este artigo objetiva estabelecer uma possível relação entre as noções de arquivo e de memória para avaliar as possibilidades teóricas de uma aproximação dialética entre os pensamentos de Foucault e Luhmann. Para tanto, pretende-se explicitar a noção de arquivo como sistema de discursividade e a ideia de memória como uma estrutura seletiva de construção do próprio sentido da história. Como resultado, espera-se verificar essa conexão entre os pensamentos de Foucault e Luhmann, de modo a enriquecer as pesquisas históricas, especialmente diante da constatação, em ambos, de que a história não é uma questão de verdade, mas do resultado de

174 uma relação de poder, de um discurso que venceu, de uma pretensão de verdade que se impôs em determinada época e lugar e que, exatamente por isso, pode ter o seu sentido sempre reconstruído a partir do presente.

\section{História, arquivos e 0 arquivo}

Falar de história, arquivo e memória pressupõe um ponto de partida paradoxal. Pois falaremos de um começo sempre já começado. Uma origem ou um início sempre já determinado historicamente. E de um arquivo cujo conceito já faz parte de um arquivo, bem como de uma memória que pressupõe a si mesma como realidade. O problema da autologia de qualquer discurso sobre a história então não deixa outra alternativa senão escolher, arbitrariamente, um cominitare, um início, um começo, uma origem. Entretanto, no que segue, veremos, tanto com Foucault quanto com Luhmann, que esse cominitare não é arbitrário no sentido de liberdade, mas sim no sentido do poder, no sentido de uma escolha 
altamente seletiva, coordenada por um sistema de discursividade/comunicação que regula a diferença entre arquivo e "queima de arquivo", entre memória e esquecimento.

A título de ilustração do potencial intelectivo das noções de arquivo e memória em Foucault e Luhmann, comecemos com a escolha (arbitrária) de uma pergunta histórica: nós conhecemos o direito romano? Um dos mais antigos sistemas jurídicos dos quais o mundo ocidental possui registros históricos é o direito romano. Há textos, monumentos, inscrições, enfim, arquivos históricos. Muitos registros confirmam o sentido do direito das instituições romanas. Mas nós conhecemos verdadeiramente o direito romano?

Conta-se que, no período da República, Roma chegou a ter quase 1 milhão de habitantes. Uma sociedade organizada na forma da estratificação social, severamente dividida entre patrícios e plebeus - os escravos nem contavam como "parte" da ordem social, pois integravam a categoria dos bens. Podemos imaginar a cidade de Roma com uma centena de grandes e confortáveis domus habitadas pelos patrícios e milhares de casebres e outros loci habitados pelos plebeus e peregrinos.

Sabe-se que, em determinado período da República romana, os patrícios tinham o seu jus civile, o seu direito quiritário, o direito das quiritas, dos parentes, dos consanguíneos. Enquanto que a plebe e os povos peregrinos, excluídos do jus civile, desenvolveram de modo extraoficial o seu próprio direito, o jus gentium, o direito das gentes, da "gentalha", dos "de fora". A pretoria urbana, dotada de alto status e poder de magíster, desenvolvia o direito dos patrícios. Já a pretoria peregrina, para resolver as questões jurídicas dos povos estrangeiros dominados pelos romanos, era um cargo de baixo prestígio. Praticamente uma forma de punição para um patrício que fez algo que não deveria ter feito. Uma forma de afastar um patrício da cidade de Roma por algum tempo. 
Conhecemos o direito romano? Se considerarmos que apenas os patrícios sabiam ler e escrever, então podemos supor agora que apenas conhecemos a versão "patricialista" do direito romano. Conhecemos o que Celso, Cícero, Gaio e Justiniano deixaram escrito acerca da experiência jurídica romana. Quer dizer: conhecemos apenas uma versão "patricialista" dessa história, contada pelo ponto de vista muito restrito de um grupo igualmente restrito de eruditos letrados daquela época.

Não conhecemos o direito romano contado pelo ponto de vista da plebe, dos peregrinos, dos escravos, do homo sacer. Não conhecemos o sentido da pretoria ou do cargo de pretor pelo ponto de vista de quem a ele se encontrava submisso - salvo por algumas pinturas subversivas da arte renascentista. De tudo o que acontecia no mundo jurídico romano, sabemos apenas uma pequena versão, uma pequena parte da história, um lado apenas dos múltiplos significa176 dos que todos os fatos históricos sempre carregam consigo.

Da história, nós sabemos apenas a versão de quem venceu a história. De tudo o que aconteceu no passado, sabemos apenas o lado contado pelo discurso vencedor. Pelo discurso que faz parte do grupo, da ordem, do campo, enfim, o discurso produzido por quem venceu a relação de poder que havia na época. História também é poder. A história que sabemos sempre é a história de quem venceu para contar a sua versão da história. Dificilmente sabemos a versão de quem perdeu, de quem morreu ou de quem simplesmente ficou submetido à versão vencedora.

Se isso pode ser observado a respeito do discurso genuinamente patrício sobre a experiência jurídica romana, podemos supor que também aconteça em eventos históricos mais recentes. Como na história do nazismo, do fascismo, do regime militar no Brasil e nos países da América Latina. A história da ditatura militar no Brasil não é uma história contada apenas por jovens estudantes de esquerda, geral- 
mente do sexo masculino? Como seria a história da ditatura militar contada do ponto de vista de uma mulher? Ou de alguém que morava no interior e que só via as notícias pela televisão, rádio e jornal? Como seria a história registrada por outras formas de arquivo diferentes do arquivo oficial da história?

\section{0 arquivo como sistema de discursividade}

Segundo Foucault (1996, p. 166), há um a priori histórico que desempenha o papel de unidade nas disciplinas científicas. Esse a priori histórico é o que permite a reunião de campos de discussão, unidades temáticas e identidades formais. Permite que toda uma massa de textos, sobre diversos assuntos, produzida em determinado tempo e espaço, possa ser organizada na forma do pertencimento a uma mesma formação discursiva.

Esse a priori histórico é mais do que uma identidade conceitual, como se todos os juristas se identificassem pelo simples fato de eles compartilharem as mesmas questões conceituais. E também é mais do que uma unidade temática, pois não são apenas as funções enunciativas das proposições linguísticas que definem os campos temáticos de estudos. O a priori histórico constitui a "condition de réalitê" (Foucault, 1996, p. 167) para enunciados. Não se trata simplesmente da noção de paradigma (Kuhn, 2003, p. 243) como estrutura que condiciona a validade dos enunciados. Trata-se de um pressuposto de realidade, de existência, de positividade da história. Um pressuposto de que algo realmente aconteceu, de que algo realmente foi dito ou escrito.

O a priori histórico é um conjunto de regras que determina uma prática discursiva, mas não regras exteriores à própria prática (Serres, 2006, p. 140). Regras que fazem parte da própria prática discursiva, da própria rede histórica de discursos que vão se organizando em linhas temporais, em sucessões de problemas e soluções e em unidades temáticas e problemáticas que fazem a história parecer uma 
realidade linear, uma história na qual os fatos acontecem uns depois dos outros, uns por causa dos outros.

Desse modo, o a priori histórico disciplina. Ele isola temáticas e discussões contingentes na forma de uma unidade temática organizada. Ele traça um "cordão sanitário”, que separa o que pode ser dito daquilo que não pode ser dito em determinado campo de conhecimento, em determinado contexto de fala, em determinada "disciplina" (Foucault, 1966, p. 9).

Ao contrário de uma história linear das ideias, dos fatos e das coisas que vão acontecendo de modo "disciplinado" no decorrer dos tempos, Foucault propõe re-entender a história como uma formação caracterizada por diferentes tipos de positividade, articulados por diferentes formações discursivas (Foucault, 1996, p. 169). As quais sofrem, contudo, uma inevitável e violenta seletividade na história.

Para Foucault (1996, p. 169), há sistemas que instauram enunciados discursivos como se fossem acontecimentos reais, 178 como se fossem "coisas”. Há sistemas que selecionam alguns enunciados discursivos e os transformam em história, em coisas ou "fatos" que realmente aconteceram no sentido em que aconteceram. Esse sistema de discursividade, que transforma o a priori histórico em fatos e coisas reais, construindo uma realidade histórica, é o que Foucault denomina de arquivo.

Arquivo, para Foucault (1996, p. 169), é o sistema que transforma enunciados discursivos em acontecimentos e em coisas. O arquivo é a lei do que pode e do que não pode ser dito (Foucault, 1996, p. 170). Não se trata, portanto, de arquivo no sentido apenas de registro histórico, de soma de textos guardados para a posteridade. Também não se trata apenas de instituições de guarda e conservação de memórias. $\mathrm{O}$ arquivo é um sistema de discursividade que estabelece uma conexão de certos discursos com outros certos discursos, excluindo todos os demais. É um sistema de discursividade que seleciona o que vai ser conectado à história e o que vai ser dela excluído. 
O arquivo não é memória no sentido de um registro que torna presente um fato ausente, um fato já perdido no passado distante. Tampouco é uma instituição de conservação daquilo que merece ser conservado para o futuro. $\mathrm{O}$ arquivo, para Foucault, é aquilo que define o que merece ser memorizado - e o que merece ser esquecido. É aquilo que determina o que deve ser conservado - e o que deve ser abandonado. É o sistema de discursividade que separa o que merece ser arquivado como história e o que deve ser esquecido. $\mathrm{O}$ arquivo regula o que deve ser considerado tradição e o que deve cair no esquecimento.

Conectando enunciados histórico-temáticos de acordo com suas próprias regras discursivas, o arquivo cerceia a liberdade de se usar as palavras em seus sentidos mais livres. $\mathrm{O}$ arquivo transforma o sentido das palavras em tradição, delimitando as suas possibilidades de enunciação. Juiz "incompetente" seria uma afirmação grosseira se não fosse o arquivo jurídico que regula o sentido dessa expressão no contexto particular da disciplina do direito processual, na forma de uma questão de competência funcional ou territorial para o conhecimento de determinada questio juris.

Mas o arquivo não apenas regula a conexão entre enunciados - com a exclusão de outros. Ele também regula a sua própria transformação. $\mathrm{O}$ arquivo regula inclusive o que merece ser arquivado - e o que merece ser esquecido - no futuro. Por isso, Foucault (1996, p. 171) sublinha que o arquivo "é o sistema geral da formação e da transformação dos enunciados”. Ele regula tanto a formação quanto a transformação dos enunciados discursivos.

\section{Arqueologia e diferença}

A arqueologia é o estudo do arquivo. Não é a arqueologia no sentido da busca de um começo, de um início. Tampouco a investigação geológica ou de coisas ou de outros arquétipos de povos ou civilizações antigas. Para Foucault (1996, 
p. 173), a arqueologia é a interrogação do "já dito" em sua função enunciativa e em seu pertencimento a determinada formação discursiva. A arqueologia descreve os discursos como práticas especificadas pelo arquivo.

Entretanto, há um problema reflexivo nessa pretensão descritiva do arquivo. Pois inevitavelmente fazemos parte já do arquivo que pretendemos descrever. Não é possível descrever nosso próprio arquivo, nosso próprio sistema de discursividade em que produzimos o sentido da nossa própria história, da nossa própria identidade. Pois ao tentarmos descrever nosso próprio arquivo, estaremos inevitavelmente submetidos às suas próprias regras. Se é o arquivo que regula o que pode - e o que não pode - ser dito, como podemos dizer algo sobre ele que não seja por ele previamente disciplinado? Como podemos discorrer sobre nosso arquivo se nosso discurso já estará por ele determinado?

Outras concepções teóricas procuraram dar resposta a 180 essa questão da reflexividade em geral do conhecimento. A hermenêutica filosófica de Gadamer fala em fusão de horizontes. A pragmática formal de Habermas fala em intersubjetividade, em razão comunicativa. Para Foucault (1996, p. 172), entretanto, o diálogo também se encontra inevitavelmente inserido em um sistema de discursividade, que disciplina o que pode e o que não pode ser dito. O diálogo também é resultado do arquivo.

A impressão inicial que se poderia ter, em termos de uma possível metodologia de análise do arquivo - arqueologia -, é a de que seria necessário um afastamento histórico ou um deslocamento espacial das regras discursivas do arquivo para melhor compreendê-lo. Assim, quanto mais distantes, temporal e espacialmente, dos acontecimentos históricos, melhores seriam as condições para uma compreensão imune à violência das regras do arquivo.

Entretanto, afastar-se do arquivo significa afastar-se precisamente das regras que determinam as condições 
do entendimento dos enunciados discursivos (Foucault, 1996, p. 172). Afastar-se do arquivo não imuniza o sujeito do conhecimento a respeito do seu objeto potencialmente contaminado por um sistema de discursos historicamente arquivados. Pelo contrário, esse afastamento desloca o observador para uma região inócua e homogênea da história. Desloca a descrição para uma instância ingênua dos acontecimentos históricos.

A análise do arquivo oferece uma posição privilegiada para a observação, porque ela se torna, ao mesmo tempo, próxima das nossas próprias condições de entendimento e distante de nossa atualidade. A arqueologia, assim, permite dissipar a identidade temporal que nós imaginamos existir para, a partir dessa imaginação, julgar as rupturas da história (Foucault, 1996, p. 172). Permite refletir sobre quanto de nós há sobre nossos discursos, e quanto dos outros. Permite distinguir o nosso discurso do campo mais geral do sistema de discursividade sobre o qual estamos sempre inseridos - ou sumariamente excluídos.

A distinção torna-se, assim, uma unidade analítica importante no pensamento arqueológico de Michel Foucault. Distinção essa que também, em certo sentido, aproxima-se do esquema de observação diferencialista-formal - e, por isso, pós-ontológico - de Niklas Luhmann, por ele denominado de observação de segunda ordem.

De modo muito próximo ao pensamento luhmanniano, Foucault (1996, pp. 172-73) conclui que "nós somos diferença, que nossa razão é a diferença dos discursos, nossa história, a diferença dos tempos, nosso eu, a diferença das máscaras". Assim, a diferença não é a origem esquecida e recoberta das nossas ideias presentes, "é a dispersão que somos e que fazemos" (Foucault, 1996, p. 173). Tal como em Luhmann (2007, p. 149), segundo o qual a diferença é a unidade paradoxal entre identidade e diferença. 


\section{Memória, seletividade histórica e distinção}

A mesma questão da autoaplicação recursiva do arquivo para entender o arquivo, que incomodou Foucault, também aparece nas preocupações da teoria dos sistemas sociais de Niklas Luhmann. Desde os anos de 1980, até suas obras mais recentes (Luhmann, 1991, p. 15; 2007, p. 5), um dos grandes desafios da teoria da sociedade está na capacidade de autoaplicação da teoria a ela mesma. Se uma teoria social faz parte da sociedade, a teoria que pretende descrever a sociedade precisa ser capaz também de descrever a si mesma. Precisa ser capaz de lidar com a autologia, com a autorreferência e com o paradoxo.

No campo das pesquisas históricas, Luhmann questiona, como Foucault, a suposição de que as coisas aconteçam dentro de um curso histórico. Essa suposição de que exista uma continuidade histórica sempre é realizada do ponto de vista do presente. E isso significa que a história, nessa pers-

182 pectiva tradicional, é uma história do presente, segundo as necessidades e exigências estruturais bem delimitadas do presente. Para Luhmann (2007, p. 456), o próprio sentido da história se constrói e se reconstrói no presente e no contexto sistêmico-comunicativo do observador.

A potência reflexiva do pensamento de Luhmann permite questionar como o próprio conceito de evolução produz determinados tipos de evolução. Ou como a observação de determinada transformação social transforma a sociedade. Para Luhmann, uma teoria precisa ser capaz de superar a simples observação das continuidades e das descontinuidades ou daquilo que tem mais duração, para assim poder ver as rupturas. Entre o normal e o desviante em termos de história, uma teoria precisa ser capaz de observar como é possível utilizarem-se essas distinções entre normal e desviante, entre continuidade e descontinuidade ou entre duração e ruptura, e que tipo de função essas distinções desempenham para a autodescrição da sociedade. 
Especialmente porque se tratam de distinções igualmente históricas, igualmente submetidas àquilo que elas pretendem explicar.

Para Luhmann (2007, p. 457), utilizando o conceito no sentido da matemática de Spencer-Brown (1979, p. 61), memória é um dispositivo de processamento de distinções históricas. Memória é um dispositivo que um sistema desenvolve para poder traçar uma diferença entre o que ele era antes e o que é agora. A memória é uma forma de construção do tempo. De estruturação do passado.

Tal como o arquivo em Foucault, a memória em Luhmann não é um armazenamento de dados ou informações do passado para disponibilizá-los ao futuro. Tampouco é uma instituição ou um registro de fatos, acontecimentos e coisas que merecem ser conservados. Para Luhmann, a memória é uma forma de reconstrução e de estruturação contínua do passado desde o presente. É uma forma de dar sentido às operações do presente, por meio da construção altamente seletiva das causas, origens, motivos e razões históricas das operações presentes.

A memória cumpre uma importante função de verificação e controle da consistência e da coerência das operações históricas de um sistema. Com base na memória, um sistema social constrói uma história para si mesmo, uma imagem coerente e consistente de si mesmo. A memória permite lembrar, no presente, apenas o que é importante para dar sentido às operações do presente. E permite esquecer todo o restante, todas as contradições, os non senses, os paradoxos. A memória, portanto, é lembrança e esquecimento ao mesmo tempo. Ela é um dispositivo de seleção daquilo que merece ser lembrado e daquilo que deve ser esquecido hoje. Muito embora, no futuro, a memória possa ser reconfigurada para lembrar coisas que hoje são esquecidas e esquecer "fundamentos" que hoje são importantes para dar sentido às nossas práticas. 
Sem o esquecimento, não haveria espaço para o aprendizado, tampouco para a evolução. Sem recordação, não haveria fundamento de sentido para justificar nossas práticas, nossas decisões. A memória desempenha a função de organização seletiva dessa relação entre esquecimento e recordação (Luhmann, 2007, p. 458).

Do mesmo modo que a noção de arquivo em Foucault, a memória em Luhmann também não tem a ver somente com as regras formais ou com as condições de validade de enunciados presentes. Mais do que isso, a memória também tem a ver com a própria construção da realidade dos enunciados, da realidade das operações de comunicação. Permitindo a comprovação da coerência e da consistência das operações presentes em relação aos "fundamentos" passados memorizados, a memória determina o que pode ser considerado realidade para um sistema. A memória seleciona "a realidade" a partir da qual um sistema pode olhar para o futuro (Luh184 mann, 2007, p. 460). Desse modo, a memória controla o que é realidade e o que é imaginação de um sistema.

\section{Memória social e cultura}

Uma memória social não pode, contudo, ser confundida como uma "memória coletiva". Do mesmo modo que Luhmann, também Foucault não chega a ligar o sistema de discursividade do arquivo a pessoas, a "classes dominantes" ou a grupos hegemônicos, como fizeram algumas tendências marxistas. Mas ele não deixa claro a que tipo de instância social pertence o arquivo.

Para Luhmann, a memória não é uma soma de memórias individuais, de pessoas ou de grupos sociais. Claro que cada indivíduo pode ter sua memória privada, como também as organizações e os sistemas sociais constroem e reconstroem o próprio sentido dos seus passados para melhor justificar suas operações no presente. Mas há uma memória genuinamente social. Uma memória que é social 
e que, tal como a comunicação, transcende as operações de sistemas individuais. Essa memória social apresenta-se como uma forma de "capital cultural", no sentido de Pierre Bourdieu (2006, p. 9). Algo muito próximo ao que nós chamamos atualmente de cultura (Luhmann, 2007, p. 463).

Com a invenção da escrita, a sociedade pôde liberar as memórias individuais das exigências de escolha entre lembranças e esquecimentos. A escrita transformou as memórias individuais em uma memória social - mas não necessariamente pública ou política. Textos que materializam formas de comunicação para novas formas de comunicação. Uma rede histórica de memórias muito similar à noção de arquivo de Foucault.

Contudo, Luhmann observa um fenômeno diferente no mundo contemporâneo. A partir do momento em que, com a escrita, a memória social passa a se distinguir das memórias particulares, a função de "construção de começos" (Luhmann, 2007, p. 468) torna-se generalizada em termos de comunicação social. Uma nova semântica se consolida e se confirma na prática comunicativa da sociedade, a partir da qual a memória, agora, funciona como fundamento, tanto de validade como de existência/realidade das nossas decisões no presente.

A memória, como qualquer outra forma de comunicação social, também se encontra submetida à evolução, a transformações sociais. Ela mesma é produto da evolução (Luhmann, 2007, p. 469). A memória, portanto, não é uma "representação" da realidade evolutiva. Tampouco constitui uma imagem da evolução ou do simples passar do tempo. E, por isso, a memória não pode controlar a evolução. Ela apenas pode controlar a si mesma. Ela apenas controla a diferença, realizada desde o presente, entre o que serve e o que não serve mais como fundamento para justificar um início, uma origem ou uma causa remota para uma decisão contemporânea. 
Desse modo, a memória permite deixar o futuro em aberto. Ela deixa o futuro em permanente estado de indeterminação, para que sejam possíveis "oscilações" (Spencer-Brown, 1979, p. 69) de sentido, quer dizer, para que as formas de comunicação possam, no futuro, estabelecer novas conexões de sentido. Utilizando uma terminologia de Henri Atlan (1986, p. 43), a memória permite construir atribuições de sentido à diferença entre variação e redundância, a partir da qual os acontecimentos sociais podem ser adjudicados ou como "novidades" no lado da variação ou como "repetições" no lado da redundância.

Quem comanda então a distinção entre o que é novidade e o que repetição? Quem define a diferença entre o velho já conhecido e o novo cheio de novidades? Tanto para Luhmann como para Foucault, não se trata apenas do poder de pessoas, grupos, classes, interesses etc. A imposição de uma versão arqueológica da história não é controlada por quem 186 possui o poder do arquivamento. Ela é controlada pelo próprio sistema de discursividade que caracteriza o arquivo.

Do mesmo modo para Luhmann, a memória não é simplesmente uma imagem do passado ideologicamente construída segundo os interesses de grupos hegemônicos, de classes poderosas - muito menos pelo consenso intersubjetivo no estilo da razão comunicativa de Habermas. Para Luhmann, do mesmo modo como o arquivo de Foucault estabelece as suas próprias regras, também a memória só pode comandar a si mesma segundo as exigências sistêmicas de cada época.

Naturalmente, há uma distância história e teórica entre Foucault e Luhmann que chama a atenção a essas incríveis coincidências na descrição de processos sociais de construção e consolidação de sentido. Mas uma diferença importante na teoria de Luhmann, a respeito dessa relação arquivo-memória, está na função do sistema dos mass media, como a televisão, rádio, jornais, internet, revistas e todos os demais 
meios de comunicação para as massas. Para Luhmann (2000, p. 26), os mass media não apenas constroem uma realidade do mundo segundo a sua própria lógica da novidade, do entretenimento e do dramático. Eles constroem também memória. Os mass media constroem uma imagem altamente seletiva do passado da sociedade, conectando notícias a outras notícias e, desse modo, construindo uma rede histórica de acontecimentos como memória social.

Entretanto, a realidade dos mass media não constitui uma memória social hegemônica. Segundo Luhmann, em uma sociedade funcionalmente diferenciada, na qual direito, política, religião, economia, arte, ciência, moral, diferenciam-se funcionalmente uns dos outros na forma de sistemas sociais autopoiéticos, a memória também sofre esse processo de diferenciação. Nesse tipo de sociedade, a memória social também se diferencia em subsistemas, sendo possível observar uma memória especificamente jurídica, outra memória política, outra memória econômica, religiosa e assim por diante.

Isso significa que cada sistema social pode construir e reconstruir o sentido do seu passado de modo absolutamente contingente em relação aos demais sistemas. A origem do direito, por exemplo, por ter um significado no sistema jurídico muito diferente da mesma origem tal como entendida pela economia ou pela política (Luhmann, 1993, p. 118). As causas, os inícios, as origens, podem mudar conforme se transita entre um ou outro sistema social, pois a memória, em uma sociedade funcionalmente diferenciada, também se diferencia, também se policontexturaliza (Günther, 2004, p. 3).

Cada sistema, portanto, realiza uma construção imaginária do seu próprio passado. Cada sistema social utiliza sua própria memória para controlar a validade e a realidade de si mesmo. Este é um ponto importante, no qual não há convergência entre os pensamentos de Foucault e Luhmann. 
Pois, embora Foucault não seja específico sobre isso, há passagens do seu estudo nas quais ele permite supor a possibilidade da existência de vários arquivos atuando ao mesmo tempo. Mas o que fica explícito na arqueologia de Foucault (1996, p. 171) é apenas que cada um de nós possui um próprio arquivo particular. Já a organização sistemática que faz Luhmann a respeito de uma memória jurídica, outra memória política, outra memória econômica, além das 7 bilhões de memórias individuais dos seres humanos do planeta Terra, não aparece em Foucault.

$$
\text { *** }
$$

Se a invenção da escrita transformou a memória privada em uma memória social, o que dizer da invenção da internet, que transforma a escrita limitada a meios de difusão físicos em uma escrita que circula agora em um mundo virtual abso188 lutamente instantâneo, imagético e visual? No qual as imagens já nem são mais produzidas por instâncias sociais competentes - como as antigas agências de notícias -, e sim por celulares e câmeras compactas de cidadãos comuns que presenciaram os acontecimentos? Que impactos isso produz na memória social? Que consequências isso provoca no arquivo?

Como entender a problemática da comunicação entre a pluralidade de arquivos ou de diferentes versões arquivistas da história disputando violentamente o poder de afirmação, se sequer entendemos como funciona o arquivo dos meios de comunicação de massa nessa era digital de redes sociais de internet?

No campo do direito, torna-se no mínimo interessante perguntar: como o direito - ou as organizações/instituições jurídicas, ou ainda os profissionais do direito - constrói e reconstrói sua própria memória para fundar-se a si mesmo de acordo com uma realidade útil para cada momento histórico. Como o direito procura, seletivamente, na história, 
as causas, as origens e os fundamentos úteis para justificar suas decisões no presente (Luhmann, 1993, p. 119). E como todo o restante sofre o processo de "queima de arquivo", o mal de arquivo (Derrida, 1995), a pulsão pelo esquecimento como condição de possibilidade para a elaboração da história no presente.

Como se pode ver, os estímulos teóricos dos conceitos de arquivo e memória, tal como trabalhados, respectivamente, por Foucault e Luhmann, permitem o desenvolvimento e o desdobramento de um tipo diferente de pesquisas, que perguntam pelas condições de possibilidade da própria invenção da história. Da invenção contingente das origens, dos fundamentos, dos princípios - e da destruição de todo um outro lado da história que fica no lado do não dito, no lado do esquecimento, da descontinuidade, do a-histórico.

\section{Rafael Lazzarotto Simioni}

é professor da pós-graduação em Direito da Faculdade de Direito do Sul de Minas (FDSM) e da pós-graduação em Bioética da Universidade do Vale do Sapucaí (Univás); e lidera o Grupo de Pesquisa Margens do Direito da FDSM.

\section{Bibliografia}

ATLAN, H. 1986. Entre le cristal et la fumée. Essai sur l'organisation du vivant. Paris: Seuil.

BOURDIEU, P. 2006. O poder simbólico. Tradução de Fernando Tomaz. 9. ed. Rio de Janeiro: Bertrand Brasil.

DERRIDA, J. 1995. Mal d'archive: une impression freudienne. Paris: Galilée.

FOUCAULT, M. 1966. Les mots et les choses: une archéologie des sciences humaines. Paris: Gallimard. 1996. L'archéologie du savoir. Paris: Gallimard.

GÜNTHER, G. 2004. "Life as polycontexturality". Vordenker. Disponível em: <http://www.vordenker.de/ggphilosophy/gg_life_as_ polycontexturality.pdf $>$. Acesso em: 10 jan. 2016.

KUHN, T. S. 2003. A estrutura das revoluções científicas. Tradução de Beatriz Vianna Boeira e Nelson Boeira. 8. ed. São Paulo: Perspectiva. 
LUHMANN, N. 1991. Soziale Systeme: Grundriss einer allgemeinen

Theorie. Frankfurt a.M.: Suhrkamp. . 1993. Das Recht der Gesellschaft. Frankfurt a.M.: Suhrkamp. . 2000. La realidad de los medios de masas. Tradução de Javier Torres

Nafarrate. Barcelona/Ciudad de México: Anthropos/Universidad Iberoamericana. 2007. La sociedad de la sociedad. Tradução de Javier Torres Nafarrate. Ciudad de México: Herder/Universidad Iberoamericana.

SERRES, A. 2006. "L'Archéologie du savoir: la dimension critique". In: CHEVALIER, Y.; LONEUX, C. (éds.). Foucault à l'œuvre. Deux années de lecture foucaldienne dans un laboratoire de SHS. Belgique: Editions Modulaires Européennes.

SPENCER-BROWN, G. 1979. Laws of forms. New York: Dutton. 


\section{ARQUIVO, HISTÓRIA E MEMÓRIA: POSSIBILIDADES DE DIÁLOGO ENTRE LUHMANN E FOUCAULT}

\section{RAFAEL LAZZAROTTO SIMIONI}

Resumo: Michel Foucault desenvolveu uma das mais sofisticadas e sensíveis formas de entendimento das estruturas discursivas da sociedade contemporânea. Outra teoria desse quilate é o pensamento sistêmico-autopoiético de Niklas Luhmann, que possui alguns pontos coincidentes com o pensamento de Foucault, mas cujas perspectivas teóricas são tão diferentes que, colocadas lado a lado, as teorias se mostram reciprocamente incomensuráveis em termos conceituais e apenas comparáveis em termos metafóricos. Entretanto, a noção de arquivo em Foucault permite uma conexão com o conceito de memória em Luhmann, oportunizando uma aproximação dialética que potencializa um tipo de questionamento cientificamente sofisticado, especialmente para pesquisas históricas.

Palavras-chave: Arquivo; Memória; História; Niklas Luhmann; Michel Foucault.

\section{ARCHIVE, HISTORY AND MEMORY: POSSIBILITIES OF DIALOGUE BETWEEN LUHMANN AND FOUCAULT}

Abstract: Michel Foucault developed one sophisticated and sensitive ways of understanding the discursive structures of the contemporary society. Another theory of this type is the Niklas Luhmann's autopoietic systems, which has some overlapping points with the thought of Foucault, but whose theoretical perspectives are so different that, side by side, the theories are immeasurable in the conceptually levels and only comparable in the metaphorically levels. However, the "Archive" notion in Foucault allows a connection with the concept of memory in Luhmann, providing opportunities for a dialectical approach, especially for historical research.

Keywords: Archive; Memory; History; Niklas Luhmann; Michel Foucault. Recebido: 23/06/2015 Aprovado: 04/12/2015 